\title{
Desafíos de la responsabilidad administrativa ambiental en Cuba
}

\author{
Challenges of environmental administrative \\ responsibility in Cuba
}

\author{
Yaraí Toledo Barrios ${ }^{1}$ y Daimar Cánovas González ${ }^{2}$ \\ Universidad de La Habana - Cuba
}

Revista Derechos en Acción ISSN 2525-1678/ e-ISSN 2525-1686

Año 5/Nº 17 Primavera 2020 (21 septiembre a 20 diciembre), 710-742

DOl: https://doi.org/10.24215/25251678e475

Recibido: 01/10/2020

Aprobado: 01/12/2020

Resumen: En el presente trabajo se realiza un análisis de los desafíos que en materia de responsabilidad administrativa ambiental se le presentan a Cuba hoy, teniendo en cuenta las nuevas proyecciones en materia de desarrollo económico y social. En este sentido se aborda lo relativo a la actuación de la Administración en materia ambiental y el papel que le corresponde a la misma en el logro de una protección efectiva del ambiente. Igualmente, se realiza un breve recorrido por las cuestiones teóricas de trascendencia en el ámbito de la responsabilidad ambiental en sentido general, con referencias al plano internacional y nacional. En un segundo momento el trabajo se centra en el caso específico de la responsabilidad administrativa ambiental, con énfasis en el contenido del Decreto Ley 200/1999 «De las Contravenciones en materia de medio ambiente». Se realiza una valoración en torno a la regulación actual de la responsabilidad administrativa ambiental y

\footnotetext{
1 Profesora de Derecho Ambiental, Facultad de Derecho, Universidad de La Habana, yarai@ lex.uh.cu (ORCID: https://orcid.org/0000-0002-6683-8434).

2 Profesor Titular, Facultad de Derecho, Universidad de La Habana. Director Instituto de Ecología y Sistemática, daimar@ecologia.cu (ORCID: https://orcid.org/0000-0002-1436-8661).
} 
se esbozan los principales desafíos que desde nuestra consideración enfrenta hoy Cuba en este ámbito.

Palabras clave: ambiente, responsabilidad administrativa, Administración, desafíos

\begin{abstract}
In this paper, an analysis is made of the challenges regarding environmental administrative liability that are presented to Cuba today, taking into account the new projections regarding economic and social development. In this sense, it deals with the actions of the Administration in environmental matters and the role that corresponds to it in achieving effective protection of the environment. Likewise, a brief tour of the theoretical issues of importance in the field of environmental responsibility in a general sense, with references to the international and national level, is made. In a second moment, the work focuses on the specific case of environmental administrative responsibility, with emphasis on the content of Decree-Law 200/1999 "On Environmental Contraventions". An assessment is made around the current regulation of environmental administrative liability and the main challenges that Cuba is facing today in this field are outlined.
\end{abstract}

Keywords: environment, administrative liability, administration, challenges

\title{
I. La actuación de la Administración en materia ambiental
}

El fundamento último de la actividad administrativa en materia ambiental hay que buscarla, en primer lugar, en el texto constitucional. Es la Carta Magna la que define y encuadra el rol de la Administración Pública en la tutela del ambiente, como garante de la preservación de esos bienes públicos y del disfrute del derecho a un medio ambiente sano. Y ello no es una actividad más que se realiza en beneficio general, sino que se constituye en rasgo central del Estado de Derecho en la contemporaneidad.

La noción de Estado constitucional de Derecho se ha identificado como la forma más evolucionada dentro de las concepciones sobre el Estado de Derecho, en tanto implica una noción dinámica e integradora en la cual se le reconoce a la 
Constitución de la República su supremacía, y el ordenamiento jurídico está abierto a nuevos valores y principios de relevancia social $^{3}$. En ella se integran los logros del llamado Estado democrático de Derecho, que reconoce la facultad de los ciudadanos de participar en la decisión de los asuntos públicos de forma creciente, así como del Estado social de Derecho, que implica el refuerzo de los órganos ejecutivos y administrativos, con vistas a garantizar los derechos sociales, nacidos en la primera mitad del siglo XX.

Sin embargo, hoy no puede afirmarse la existencia de un verdadero Estado de Derecho, que no sea al mismo tiempo Estado Ambiental de Derecho. Los textos constitucionales imponen al Estado el deber de tutelar el ambiente, y algunos de sus elementos integrantes, al mismo tiempo que reconocen a los ciudadanos el derecho a un medio ambiente sano. El Estado de Derecho Ambiental es la respuesta del Estado a la crisis ambiental que pone en peligro la propia supervivencia de la especie humana y del planeta entero. No hay forma de superar esa situación límite que sujetar al Estado a las reglas del Derecho Ambiental, que encauza los esfuerzos para salir de la crisis ambiental.

A pesar de que ciertamente se trata de una construcción teórica, las huellas del mismo pueden ser leídas también en la Constitución cubana de $2019^{4}$, pues no se trata de que el Estado de Derecho Ambiental sea reconocible en tal o cual ordenamiento, sino que la eficacia de la legislación ambiental nacional puede acercarnos o alejarnos de dicha meta. En la misma medida en que el artículo 75 constitucional reconoce el desarrollo económico y social sostenible como objetivo de la nación, existe la obligación estatal no solo de asegurar el disfrute de los derechos garantizados en el texto a las generaciones

3 Villagrán Escobar, Víctor Manuel, La cultura de la legalidad en México - Teoría, realidad y perspectivas, $2^{a}$ edición, Editorial Aldea Global, Chihuahua, 2017, p. 55.

4 Vid. Constitución de la República de Cuba, de 10 de abril de 2019, Gaceta Oficial de la República de Cuba, Edición Extraordinaria, Número 5, de 10 de abril de 2019. 
presentes, sino que la tutela de extiende hacia las generaciones futuras, las que ostentan el derecho de disfrutar de un ambiente al menos con similar calidad al existente en la actualidad. A ello hay que unir la formulación del derecho a un medio ambiente sano, que, si bien no cristalizó en la reforma de 1992, fue interpretado como una consecuencia suya en la Ley de Medio Ambiente, de 11 de julio de 1997 y hoy se encuentra reconocido expresamente en el texto constitucional vigente.

Aunque continuó ausente del texto constitucional de $1976^{5}$ el reconocimiento explícito del derecho a un medio ambiente sano hasta febrero de 2019, se defendió su existencia partiendo de lo establecido en el artículo 27, pues puede plantearse que, al establecer dicho texto la obligación del Estado y los ciudadanos de proteger el medio ambiente, el mismo se consagra como un derecho constitucionalmente protegido, elevado a la categoría de principio configurativo del ordenamiento político y jurídico. Se toma como fundamento el carácter necesario de que a cada deber le corresponda un derecho correlativo. Si concebimos los derechos subjetivos, en tanto categoría general, como conjunto de facultades que posibilitan a su titular la exigencia de determinadas conductas a otros sujetos, éstos tendrían entonces un deber a partir del cual se les puede exigir un comportamiento determinado. Como acertadamente afirma ARANDA OrTEga, “...la principal consecuencia de esta consideración recíproca entre el derecho fundamental y el deber de protección, es que una vez creado uno, implícitamente debiera dar origen al otro, con independencia del texto escrito"6.

La ausencia en el texto fundamental de 1976 se trató de cubrir con la promulgación de la Ley 81, Ley de Medio Ambiente, cuyo artículo 4 reconoce el derecho a un medio ambiente sano,

\footnotetext{
5 Constitución de la República de Cuba, de 24 de febrero de 1976, reformada en 1978, 1992 y 2002, Gaceta Oficial de la República de Cuba, Edición Extraordinaria, Número 3, de 31 de enero de 2003. (DEROGADA).

6 Aranda Ortega, Jorge, “El Estado de Derecho Ambiental: Concepto y perspectivas en Chile", en Justicia Ambiental, Chile, 2013, p. 33.
} 
como "derecho fundamental". Si bien no era este el lugar para hacer tal declaración, ello dio pie para una interpretación más consecuente del texto constitucional, y ha sido la base de todo avance legislativo que se ha emprendido posteriormente en esta materia. Hoy día el derecho al disfrute de un medio ambiente sano se encuentra reconocido explícitamente en el la Carta Magna de 2019, así como el deber del estado y de los ciudadanos de proteger el bien jurídico medio ambiente. La actividad administrativa en relación a la tutela del ambiente tiene como cauce, pues, el reconocimiento de este derecho, pero también el deber de protección impuesto desde la norma fundamental en cuanto al medio ambiente, y los recursos naturales al Estado, en primer orden. La actuación estatal estará vinculada entonces al Derecho Ambiental, y este se convierte en límite de esa propia actuación. En definitiva, se trata de que la vida pueda proyectarse hacia el futuro, y esa es condición de posibilidad de cualquier otro bien o derecho.

Pero uno de los más grandes retos del Derecho Ambiental es el de su eficacia, por lo que dichos preceptos constitucionales no pueden quedar en meras declaraciones, sino que deben hacerse operativos en la actuación cotidiana de la Administración. Esta puede decirse que ejecuta la legislación ambiental en el ejercicio de la potestad reglamentaria, dictando actos jurídicos como cuando expide una licencia o autorización, aprobando planes de diversa naturaleza o prestando servicios públicos. Y en todo ello debe estar orientada por el desarrollo sostenible como principio y meta que guíe su actuación, más allá de la sujeción formal ${ }^{7}$.

Una sentencia del Tribunal Constitucional español puede servir de orientación para la interpretación del artículo 75 constitucional y, por tanto, aportar criterios para la actuación administrativa en materia ambiental. De acuerdo a la sentencia

7 Jordano Fraga, Jesús, "La Administración en el Estado ambiental de Derecho", en Revista de Administración Pública, número 173, 2007, p. 101. 
No. 62, de fecha tan temprana como el 4 de noviembre de 1982, esclareciendo el sentido del artículo 42 de la Constitución española, se concluye que el modelo de desarrollo que se persigue es de tipo cualitativo y no meramente cuantitativo, basado en el simple crecimiento económico. Ello implica, claro está, cierta limitación en las actividades económicas, no solo extractivas, ni en el reducido espacio de las áreas protegidas.

Desarrollo y protección ambiental son dos objetivos perseguidos también por el ordenamiento jurídico cubano, y ello obliga a cierta labor de ponderación que deberá realizar el legislador ordinario, en primer lugar, y después la Administración Pública en cada caso concreto. La consideración de la dimensión ambiental tiene unas implicaciones directas para la actividad administrativa, al constituir el ambiente un bien constitucionalmente protegido, cuya relevancia no puede desconocerse.

Las distintas actividades económicas se realizan en el territorio nacional por los sujetos económicos autorizados, pero la Administración, por ejemplo, puede discriminar positivamente determinadas actividades, debido a su menor impacto ambiental, sin que ello signifique una vulneración del principio de igualdad. Así lo reconoce la sentencia No. 25, de 3 de febrero de 1989, también del Tribunal Constitucional español, pero en la práctica cubana se cuenta con ejemplos de ese tipo de discriminación positiva. La Ley 113, Ley del Sistema Tributario, que establece un impuesto por la utilización y explotación de los recursos forestales y la fauna silvestre (artículo 267), gravando actividades como el aprovechamiento maderero y de productos no madereros como resinas, cortezas, semillas, entre otros ${ }^{8}$.

Sin embargo, la sostenibilidad del desarrollo puede ser puesta en peligro también por la actividad administrativa. Por ello las normas de Derecho Ambiental deben ser normas de

8 Ley 113, del Sistema Tributario, de 23 de julio de 2012. Gaceta Oficial de República, Edición Ordinaria, Número 53, 21 de noviembre de 2012 
aplicación directa. Cualquier reglamento o acto administrativo que no tenga en cuenta esta dimensión ambiental y persiga una concepción de crecimiento económico a ultranza, puede ser catalogado como nulo de pleno derecho, en tanto vulnera uno de los principios configurativos del Estado cubano.

Incluso un acto que haya sido realizado amparado en determinada autorización administrativa, si provoca un daño ambiental, genera responsabilidad civil, obligando a la reparación correspondiente". "La licencia concedida no es en modo alguno una patente de corso que cubra de legalidad eventuales daños provocados por el sujeto autorizado. La Ley de Medio Ambiente establece en su artículo 25 que el otorgamiento de la licencia ambiental no exime al licenciatario de la obligación de proteger de manera efectiva el medio ambiente, ni de las responsabilidades administrativas, civiles y penales en que pueda incurrir" ${ }^{10}$.

También es consecuencia del Estado de Derecho Ambiental el control sobre las decisiones de la Administración, de modo que exista cada vez un menor margen de discrecionalidad en su actuación. Si bien la discrecionalidad es necesaria, se trata de arbitrar medios para que no se convierta en arbitrariedad, sobre todo en aquellos espacios en que la discrecionalidad puede tener un impacto ambiental significativo. Piénsese en el ejercicio de la potestad reglamentaria de la Administración, las evaluaciones de impacto ambiental, o la aprobación de los planes y esquemas de ordenamiento ambiental y territorial.

Eso sí, dicho control no puede ser meramente formal, sino sustantivo, de modo que el órgano jurisdiccional pueda controlar la calidad de los estudios de impacto ambiental, su rigurosidad

9 Así lo reconocen las sentencias del Tribunal Supremo español de 30 de octubre de 1963, 12 de diciembre de 1980, y 16 de enero de 1989.

10 Cánovas González, Daimar, "Licencia ambiental y sistemas de responsabilidad" en, Álvarez-Tabío Albo, Ana María y Andry Matilla Correa (coordinadores), El Derecho público en Cuba a comienzos del siglo XXI - Homenaje al Dr. Fernando Álvarez Tabío, Editorial UH, La Habana, 2011, pp. 289-299. 
científica, su racionalidad, así como la presencia en la documentación de la información relevante sobre cada caso concreto. El Estado ambiental de Derecho exige no solo la sujeción formal de la Administración, sino un verdadero encuadramiento de su actividad en los marcos de las normas sustantivas ambientales.

Por último, aunque no de menor importancia, la Administración debe establecer conductas que lesionen o pongan en peligro el ambiente o alguno de sus elementos, y asociar a ellas unas sanciones, que tengan la entidad suficiente como para disuadir de dichas conductas, denominadas contravenciones. La potestad sancionadora de la Administración hará su contribución al desarrollo sostenible en la medida en que las sanciones previstas jueguen el rol preventivo a que están llamadas. La responsabilidad administrativa, en el marco de los sistemas de responsabilidad, tiene un lugar insustituible, y así la ha utilizado ampliamente en el país el Ministerio de Ciencia, Tecnología y Medio Ambiente (CITMA).

\section{Repensando el lugar de la Administración ambiental}

La última década del siglo XX y las primeras del siglo XXI han sido testigos de un amplio debate sobre el lugar de la Administración, especialmente en el ámbito industrial y ambiental. Los aires del neoliberalismo, con sus concepciones en torno a un Estado mínimo, que deje en libertad las fuerzas del mercado, se han dejado sentir en las ideas en torno al lugar de la Administración Pública, en especial ambiental. Se ha pasado así de un modelo administrativo de intervención a uno de mero control, donde la iniciativa privada ocupa espacios antes exclusivos de la actividad estatal. Y no se trata solo de actividades económicas estratégicas que han sido abandonadas por las empresas públicas, sino que los particulares han ocupado posiciones en el entramado legal e institucional que conlleva la aplicación de las normas ambientales. Síntomas de ese fenómeno son las entidades privadas colaboradoras de la Administración ambiental en el control directo sobre el cumplimiento de la normativa, 
agencias que realizan funciones técnicas de comprobación, como las certificadoras de normas de calidad, o incluso cuando entes empresariales realizan los estudios de impacto ambiental de los proyectos de obra o actividad $^{11}$.

Los argumentos utilizados para este cambio de paradigma, coinciden con los blandidos por el liberalismo en cualquier ámbito, lo mismo en la economía que en la prestación de servicios públicos. Se alega la ineficacia de la gestión de la burocracia administrativa y del dictado de disposiciones generales de obligatorio cumplimiento para todos, el exceso de litigiosidad que conlleva dar cumplimiento a dichas normas, entre otros. No obstante, recientes estudios han señalado la falsedad de estos presupuestos. Ni se reducen los litigios ni el tiempo de ejecución de las disposiciones legales. Al contrario, se establecen negociaciones directas entre la Administración y los diversos grupos de interés, se alcanzan normas consensuadas y particulares de gran ambigüedad, y se saca del debate público aspectos importantes, sobre los cuales es necesario lograr consensos ${ }^{12}$.

En un contexto de creciente inversión extranjera, y de apertura a nuevos actores económicos en el ámbito nacional, la Administración ambiental cubana podría aprovechar las ventajas de algunos de estos nuevos instrumentos, pero nunca perder de vista su función esencial de salvaguarda de los bienes e intereses de la colectividad. Si bien es posible alcanzar acuerdos negociados con determinados actores, ello no puede mermar la eficacia general de la ley, pues en última instancia dichos acuerdos son voluntarios, y los riesgos de ineficacia ante su incumplimiento se mantendrían. Si el derecho a un medio ambiente sano forma parte del elenco de derechos reconocidos a los cubanos, no es posible que se pacte sobre ese bien público al margen de la participación ciudadana, sin que sea posible

\footnotetext{
11 Jordano Fraga, Jesús, "La Administración..., op. cit., p. 123.

12 Morris, YANDlE and Dorchack, "Choosing how to regulate", in Harvard Environmental Law Review, volume 29, 2005, pp. 180-202.
} 
ejercitar los procedimientos previstos para impugnar cualquier acto administrativo (artículo 670 de la Ley de Procedimiento Civil, Administrativo, Laboral y Económico). La Administración desplazaría su actividad desde el Derecho Público hacia el Derecho Privado, en el que actúa en igualdad de condiciones, pero sin las herramientas necesarias para la tutela del ambiente.

Quienes pretenden imponer la autoregulación y los acuerdos con la Administración a toda costa olvidan que estos acuerdos, al menos en materia ambiental, entrarían en contradicción con principios esenciales al Derecho Ambiental. El acceso a la justicia se vería frustrado, en tanto se impediría la imposición de demandas contra dichas empresas durante la vigencia del acuerdo por parte de terceros, no firmantes del acuerdo, pero quizás lesionados en sus derechos. Además, pactar la no aplicación de regulaciones de forma temporal, sean estas presentes o futuras, constituiría, además de una cesión de soberanía en todo punto inconstitucional, una vulneración al principio de precaución reconocido en el artículo 4 de la Ley de Medio Ambiente, por cuanto su aplicación excluiría cualquier decisión que permita dañar el ambiente de forma legal en un futuro, haciendo caso omiso a las modificaciones legislativas y los avances de la ciencia.

La utilización de nuevos mecanismos, como los económicos, por los cuales los propios destinatarios de la norma se hagan cargo de su cumplimiento, y del avance de los indicadores ambientales, no hace en modo alguno innecesarios a los instrumentos llamados de "comando y control", entre los cuales se encuentra la responsabilidad administrativa. Esta debe ser la garantía de que la Administración ambiental actuará frente a la vulneración de los mandatos legales o reglamentarios, imponiendo las sanciones correspondientes, cuando los mecanismos voluntarios hayan fallado o se hayan mostrado insuficientes. La responsabilidad administrativa ha sido parte importante del Derecho Ambiental cubano hasta el momento, y deberá seguir siéndolo, aunque haciendo las adecuaciones que conduzcan a 
una mayor eficiencia y eficacia. Precisamente a determinar el lugar y función del sistema de responsabilidad administrativa, en el contexto del resto de los sistemas de responsabilidad, se dedican las páginas siguientes.

\section{La responsabilidad ambiental en Cuba. Breves comentarios}

Al igual que el desarrollo del Derecho Ambiental, el cual se enmarca esencialmente en la esfera del Derecho Internacional, la responsabilidad ambiental ha tenido su manifestación en foros internacionales cuyo centro ha sido la protección del ambiente. Así el Principio $13^{13}$ de la Declaración de Río sobre el Medio Ambiente y el Desarrollo de 1992 se refiere a la necesidad de que los Estados adopten legislaciones sobre responsabilidad e indemnización por daño ambiental tanto en el ámbito nacional como internacional.

En suelo patrio la responsabilidad ambiental ha sido reconocida como un instrumento de la gestión ambiental a partir de lo establecido en el artículo 18 de la Ley 81 de 1997, "Ley de Medio Ambiente"14. A partir de lo preceptuado en dicha norma, es posible evidenciar cómo para lograr la exigencia de responsabilidad en este ámbito, la Ley 81 se apoya en las reglas propias del Derecho Civil, Penal y Administrativo, al precisar como regímenes de responsabilidad los correspondientes a estas ramas del Derecho. Ello es muestra de cómo el Derecho Ambiental se sirve de otras disciplinas jurídicas, que aun cuando el bien jurídico que protegen no es precisamente el

\footnotetext{
13 “Los Estados deberán desarrollar la legislación nacional relativa a la responsabilidad y la indemnización respecto de las víctimas de la contaminación y otros daños ambientales. Los Estados deberán cooperar asimismo de manera expedita y más decidida en la elaboración de nuevas leyes internacionales sobre responsabilidad e indemnización por los efectos adversos de los daños ambientales causados por las actividades realizadas dentro de su jurisdicción, o bajo su control, en zonas situadas fuera de su jurisdicción".

14 Ley No. 81, de 11 de julio de 1997, Del Medio Ambiente, Gaceta Oficial de la República de Cuba, Edición Extraordinaria, Número 7.
} 
ambiente, su utilización, a estos fines concretos, puede resultar efectiva. Importante tener en cuenta que estas cuestiones, antes del reconocimiento del Derecho Ambiental como rama del Derecho, eran reguladas por estas disciplinas, en ausencia de regla específicas o sin la necesaria adaptación al objeto de protección.

El Libro Blanco sobre responsabilidad ambiental de la Comisión Europea al referirse a los propósitos que se persiguen con la exigencia de responsabilidad establece “...la responsabilidad ambiental tiene por objeto obligar al causante de daños al medio ambiente (el contaminador) a pagar la reparación de tales daños"15. Asimismo expresa “...en ausencia de un régimen de responsabilidad, el incumplimiento de las normas y procedimientos vigentes sólo puede entrañar una mera sanción de carácter administrativo o penal" ${ }^{16}$. Partiendo de lo antes expuesto se hace necesario precisar dos cuestiones fundamentales, en primer lugar, se hace referencia a la configuración de la responsabilidad ambiental solo a partir de la existencia de un daño por lo cual se circunscribe únicamente a la responsabilidad civil, segunda cuestión, como consecuencia de ello no se contemplan dentro del régimen de responsabilidad ambiental los sistemas de responsabilidad administrativo y penal, los cuales se excluyen de forma expresa.

Como se ha afirmado, la Directiva 2004/35/CE del Parlamento Europeo y del Consejo, sobre responsabilidad ambiental en relación con la prevención y reparación de daños ambientales, de 21 de abril de 2004, que constituye la concreción de las ideas expuestas en el Libro Blanco, no resulta ejemplo de una responsabilidad ambiental separada de la civil, sino del establecimiento de un régimen específico para los daños ambientales puros, distintos de los que afectan simultáneamente

15 Comisión EuropeA, Libro Blanco sobre responsabilidad ambiental, Oficina de Publicaciones Oficiales de las Comunidades Europeas, Luxemburgo, 2000, p. 13. Disponible en: http:// ec.europa.eu/environment/legal/liability/pdf/, consultado 1 de agosto de 2020, 3:00pm.

16 Comisión Europea, Libro Blanco sobre..., op.cit, p.13. 
a la salud de las personas o a su patrimonio. En modo alguno dicho régimen sustituye el de responsabilidad civil por daño ambiental, sino que lo completa y modifica en ciertos aspectos, con el objetivo de alcanzar una tutela más efectiva ${ }^{17}$.

A fin de lograr un concepto que se muestre a tono con el sistema de responsabilidad ambiental cubano, resulta sugerente lo señalado por CÁNovas González "El sistema de responsabilidad es el régimen jurídico que se establece como consecuencia de un daño o infracción de una norma, con el fin de restaurar el objeto del daño o la infracción a la situación anterior, sancionar al agente comisor del acto, y prevenir de esa manera futuras conductas semejantes. De esa forma se engloban en un solo haz las principales finalidades de las distintas formas de responsabilidad civil, administrativa o penal"18. Esta conceptualización permite visualizar la esencia del régimen de responsabilidad ambiental en Cuba, el cual se despliega a través de tres regímenes diferentes ya mencionados, donde dos de ellos no dependen de la existencia de un daño sino de la infracción de una norma.

El sistema de responsabilidad civil ha sido reconocido como un mecanismo de reparación del daño ambiental, teniendo por cometido esencial generar la obligación de reparar los daños y perjuicios que se ocasionen. En la Ley de Medio Ambiente encontramos refrendado este tipo de responsabilidad en el Capítulo XII del Título Tercero, regulación que no resulta del todo completa a partir del contenido que desarrolla en apenas cinco artículos. Sobre la posibilidad de aplicar supletoriamente el Código Civil Cubano, ante el contenido limitado que sobre la

\footnotetext{
17 Lozano Cutanda, Blanca, "La responsabilidad por daños ambientales: la situación actual y el nuevo sistema de 'Responsabilidad de Derecho Público' que introduce la Directiva 2004/35/CE", en Medio Ambiente \& Derecho. Revista Electrónica de Derecho Ambiental, número 12-13, diciembre de 2005 (http://huespedes.cica.es/aliens/gimadus, consultado el 29 de octubre de 2017).

18 CÁnovas GonzÁlez, Daimar, La responsabilidad por daños ambientales en la República de Cuba, Ponencia presentada en el III Taller Legislativo Ambiental, en Chichiriviche, Estado Falcón, Venezuela, 26 de octubre de 2007, p.3.
} 
responsabilidad en este ámbito brinda la Ley 81, compartimos el criterio de Toledano Cordero y Muños Alfonso al afirmar "No hay ninguna antinomia entre las estipulaciones de ambas normas, sino que lo que se presenta es una incongruencia entre ambos textos legales. La aplicación de las formas de reparación previstas en el Código Civil no contradice el espíritu de la Ley del Medio Ambiente, sino que, por el contrario, la complementa y refuerza. Por tanto, puede perfectamente admitirse la aplicación del principio de supletoriedad"19. Importante resaltar en este sentido que acogemos esta solución en aras de suplir los vacíos que en este sentido se suscitan, sin embargo, lo más atinado y a lo que se aspira es poder contar con un régimen propio de responsabilidad civil en materia ambiental acorde a las características especiales que revisten los daños ambientales y esta rama del Derecho.

Otro aspecto llama la atención en materia de responsabilidad civil y es en lo relativo a la forma en que queda definido el daño en el artículo 8 de la Ley 81 “...toda pérdida, disminución, deterioro o menoscabo significativo, inferido al medio ambiente o a uno o más de sus componentes, que se produce contraviniendo una norma o disposición jurídica”. Específicamente, con respecto al requisito de la antijuricidad que se exige para que se configure el daño ambiental, precisa tiene que ser un acto que directamente vulnere una norma concreta y no un acto contrario a Derecho, si la responsabilidad nace a partir del daño o de la infracción no tiene sentido alguno incluir dentro de la definición del daño la propia infracción, con lo cual confunde los distintos tipos de responsabilidad. Además, coloca la antijuricidad en la vulneración de la norma y no en el propio acto dañoso, posibilitando con ello que ante una afectación a un elemento del ambiente que no esté previsto en una norma concreta, al no existir daño, no se genere ni se pueda exigir

\footnotetext{
19 Toledano Cordero, Dagniselys y Muños Alfonso, Yisel, "La Responsabilidad ambiental” en, Viamontes Guilebaux, Eulalia (coordinadora), Derecho Ambiental Cubano, Segunda edición, Editorial Félix Varela, La Habana, Cuba, 2007, p 422.
} 
responsabilidad. Ciertamente el sistema de responsabilidad que queda reflejado en dicho precepto no es el civil, a pesar de la pretensión del legislador, puesto que para que se configure la responsabilidad penal o administrativa tiene que haber una conducta tipificada ya sea como contravención o como delito, de ahí que esa definición satisfaga las exigencias de estos últimos regímenes, pero no las de aquel.

La denominada responsabilidad penal en materia ambiental tiene una naturaleza eminentemente punitiva y nace a partir de la tipificación de conductas previstas como delitos en una norma penal. Las conductas para que sean tipificadas como hechos delictivos tienen que revestir un alto grado de peligrosidad social. No olvidemos que el Derecho Penal, dados sus caracteres, se configura como un derecho de intervención mínima y su aplicación debe ser de última ratio.

La inclusión de la tutela ambiental en los códigos penales pretende además, junto a una elevación de los efectos de prevención general -negativa-, reactivar la conciencia del público sobre el daño social de los ataques al ambiente, y reafirmar la aceptación de bienes jurídicos ambientales autónomos con el mismo rango que los clásicos bienes jurídicos individuales ${ }^{20}$.

La responsabilidad penal ambiental se encuentra regulada en la Ley de Medio Ambiente en un único artículo, el cual se limita exclusivamente a conceptualizar el delito ambiental y remitir a lo dispuesto en la legislación penal vigente. Infelizmente el Código Penal cubano no prevé al medio ambiente como un bien jurídico específico por lo cual no queda protegido directamente. Es a partir de la protección que le brinda la norma penal a otros bienes como la vida, la salud, la economía que puede presumirse una protección indirecta al ambiente, protección que se encuentra dispersa al no existir un título independiente que recoja este tipo de delitos.

20 Hernández Pozo, Israel, "Derecho Penal y protección al medio ambiente", en Autores varios, Derecho y medio ambiente, Editorial Pablo de la Torriente, 2012, pp.201-202. 
El tratamiento de los delitos relacionados con la protección del medio ambiente en el Código Penal no es homogéneo. Así podemos encontrar indistintamente delitos de peligro o de resultado, la exigencia o no del elemento intencional para la tipificación del ilícito penal. Las circunstancias agravantes de la responsabilidad penal previstas no todas pueden ser aplicadas a este tipo de delitos. La mayoría de las sanciones previstas en el Código Penal para las personas jurídicas coinciden con las sanciones administrativas lo que hace que una vez impuesta este tipo de sanción resulte improcedente la exigencia de responsabilidad penal ${ }^{21}$.

Ciertamente, la modificación que experimentó el Código Penal a partir de la entrada en vigor del Decreto Ley 175 de 1997 al introducir la responsabilidad de las personas jurídicas significa un paso de avance en torno a la exigencia de responsabilidad penal, la que antes de 1997 quedaba restringida a la persona natural. Sin embargo, la limitación que introduce el artículo 16.4 al excluir a la empresa estatal como sujeto penalmente responsable no resulta beneficiosa para el ambiente. Se constituye este precepto en una grave debilidad para la responsabilidad penal, debido al papel fundamental que juega en la economía del país el sector estatal, y que por tanto, tiene más posibilidades de agredir al entorno con una conducta lesiva ${ }^{22}$.

Una dificultad que enfrentamos hoy en materia de responsabilidad penal y que rebasa el marco normativo es lo relativo a la capacitación de los recursos humanos. Sin bien un régimen legal correctamente articulado puede garantizar en gran medida el funcionamiento del sistema de responsabilidad, también de suma importancia resulta la preparación de los profesionales encargados de exigir y hacer cumplir las normas ambientales, pues ellos son el cauce y motor impulsor en la aplicación de este instrumento.

21 Toledano Cordero, Dagniselys y Muños Alfonso, Yisel, “'La Responsabilidad..., op.cit, p.420.

22 CÁnovas GonzÁlez, Daimar, La responsabilidad por daños ambientales.... op.cit, p.14. 
La responsabilidad administrativa, como anteriormente se apuntó, conforma, junto al sistema de responsabilidad civil y penal, el régimen de responsabilidad ambiental en Cuba. Es posible exigir este tipo de responsabilidad ante la violación de normas de naturaleza administrativa que tienen por fin la protección del medio ambiente. Al decir de Guaranda Mendoza "La responsabilidad administrativa ambiental es aquella que se deriva de la infracción de la norma ambiental administrativa, sus normas complementarias y su reglamentación, se concreta en la aplicación de una sanción administrativa por la acción u omisión infractora, y de ella nace la obligación de reparar la agresión ocasionada, aplicar las medidas de prevención y mitigación, y asumir los costos correspondientes"23.

Necesario resaltar que para que se active el régimen contravencional en materia ambiental no tiene que generarse un daño, solo basta con que se tipifique una infracción de las previstas en la ley o disposiciones inferiores. Ello no es óbice para que, ante la existencia de un daño producto de una contravención pueda exigirse entonces por la vía de la responsabilidad civil la reparación del daño. La responsabilidad administrativa ambiental tiene una función predominantemente preventiva y educativa, de ahí que su configuración no dependa de la existencia de un actuar dañoso sino de realizar determinadas conductas tendentes a poner en peligro el estado del ambiente, ante lo cual se activa el régimen contravencional como un mecanismo preventivo del cual se vale la Administración.

Al igual que los ilícitos penales las contravenciones tienen que estar previstas con anterioridad a la realización de la conducta infractora para que pueda ser sancionada, siendo la tipicidad una de las características de este tipo de régimen. Sin embargo, lo que llega a distinguirlas de los delitos es la peligrosidad social, mientras las contravenciones son actos ilícitos de

\footnotetext{
23 Guaranda Mendoza, Wilton, "Acciones jurídicas para establecer responsabilidades por daño ambiental en el Ecuador", Fundación Regional de Asesoría en Derechos Humanos, INREDH, Serie Investigación \# 17, Quito, Ecuador, 2010, p. 76.
} 
menor peligrosidad social, los delitos sí necesitan la prevalencia de este elemento para configurarse como tall ${ }^{24}$.

No fue hasta 1979, a partir de la entrada en vigor de la Ley No. 21, Código Penal, que la materia administrativa encontró independencia de la penal. La Ley No.33 de 1981 "Protección del medio ambiente y del uso racional de los recursos naturales" fue la encargada de establecer el régimen de responsabilidad administrativa en materia ambiental. Aunque no describía de la mejor forma las infracciones, sí reconocía de forma taxativa las sanciones a aplicar a los infractores. Tras la promulgación de la Ley de Medio Ambiente, Ley 81 de 1997, el sistema de responsabilidad administrativa fue concebido como un instrumento de gestión ambiental, dedicándose los artículos 67, 68 y 69 a su regulación.

El sistema contravencional cubano en lo que a protección del ambiente concierne se caracteriza por la existencia de una multiplicidad de disposiciones jurídicas que regulan las tantas esferas específicas de protección que demanda el ambiente. Así, a partir de la sistemática seguida, el sistema de responsabilidad administrativa ambiental se compone por normas propiamente ambientales de carácter general y especial, y normativas relativamente ambientales ${ }^{25}$.

La normativa relativamente ambiental comprende aquellas regulaciones que aun cuando su objeto específico de protección no es el medio ambiente, su contenido guarda estrecha relación con este, al punto que tributa a su conservación y cuidado. A fin de ilustrar de una mejor manera este tipo de disposiciones podemos citar el Decreto 272, de 20 de febrero de 2001, "De las contravenciones en materia de ordenamiento territorial y urbanismo". La normativa propiamente ambiental de carácter especial se manifiesta muy vinculada con las esferas específicas

\footnotetext{
24 Viamontes Gullbeaux, Eulalia, Responsabilidad Administrativa Ambiental, en Autores Varios, Derecho y medio ambiente, Editorial Pablo de la Torriente, 2012, p 174.

25 Se sigue aquí, la clasificación adoptada por Viamontes GuILBEAUX, Eulalia, Responsabilidad Administrativa..., op. cit., pp.174-175.
} 
de protección del ambiente. A partir de la clasificación seguida, es posible encontrar en ellas un contenido absolutamente sancionador independiente de las normas sustantivas o en otros casos, las infracciones se encuentran conjuntamente con las normas de naturaleza sustantiva.

Las normas ambientales de carácter general, actualmente establecidas en el Decreto Ley 200, de 22 de diciembre de 1999, "De las Contravenciones en Materia de Medio Ambiente". Este cuerpo legal contiene contravenciones relativas a distintas esferas específicas de protección como las referidas a sistema de evaluación de impacto ambiental, inspección ambiental estatal, áreas protegidas, zona costera, entre otras. Al constituir el centro de este trabajo la responsabilidad administrativa en materia ambiental, sobre el contenido y aplicación de dicha disposición tratará el siguiente epígrafe.

\section{El Decreto Ley 200/1999. Un balance de su aplicación}

En cumplimiento de lo dispuesto en la Disposición Transitoria Segunda ${ }^{26}$ de la Ley de Medio Ambiente, en 1999 se adopta el ya mencionado Decreto Ley 200 "De las Contravenciones en Materia de Medio Ambiente" el cual vino a complementar las disposiciones que al respecto establecía la Ley 81, la cual, dada su naturaleza de ley marco, necesitaba de una norma reglamentaria que desarrollara el contenido en ella previsto.

En atención a lo preceptuado en el artículo 67 de la Ley de Medio Ambiente, el Decreto Ley 200/1999 reconoce la posibilidad de exigir responsabilidad administrativa tanto a las personas naturales como a las personas jurídicas, siendo ello un primer mérito a señalar. Sin embargo, producto de la redacción dada al precepto se nos presenta una primera dificultad, pues

\footnotetext{
26 "En el término de 180 días siguientes a la promulgación de la presente, el Ministerio de Ciencia, Tecnología y Medio Ambiente presentará al Consejo de Ministros la propuesta correspondiente en materia de contravenciones administrativas y normas penales aplicables de conformidad con lo expresado en la presente Ley".
} 
tal y como reza el artículo 2.2 "La responsabilidad administrativa de las personas jurídicas sujetos de este Decreto Ley es exigible cuando la conducta sea consecuencia de un acto administrativo". A partir de la lectura del precepto se pudiera inferir que el deseo del legislador fue hacer supeditar la exigencia de responsabilidad de las personas jurídicas a la realización de un acto administrativo. Entonces nos percatamos aquí del desconocimiento por parte del arquitecto de la norma de las categorías propias del Derecho Administrativo pues recordemos utilizando palabras de García de Enterría y Fernández que "...acto administrativo sería la declaración de voluntad, de juicio, de conocimiento o de deseo realizado por la Administración en ejercicio de una potestad administrativa distinta a la potestad reglamentaria" ${ }^{27}$. Siguiendo la misma línea de pensamiento GARCINI Guerra afirma que el acto administrativo, como categoría jurídico-administrativa, ha de emanar de un órgano de la Administración del Estado, ser una manifestación de voluntad de su potestad administrativa y contener una declaración concreta que produzca un efecto jurídico-administrativo inmediato ${ }^{28}$.

Sin lugar a dudas nos encontramos ante una utilización indiscriminada de la categoría "acto administrativo"; el legislador queriendo hacer alusión a las decisiones que emanan de la persona jurídica actuando como tal, a partir de su órgano de dirección ha mal utilizado el término, no siendo correcto evidentemente su uso. La buena intención del legislador estaba direccionada a establecer la responsabilidad de las personas jurídicas cuando actuaran como tal y exonerarlas de responsabilidad ante una actuación individualizada por parte de alguno de sus integrantes. Ello puede traer consigo una interpretación incorrecta del precepto en cuestión a la hora de configurarse este tipo de responsabilidad para las personas colectivas.

27 García de Enterría, E. y Fernández, T.R., Curso de Derecho Administrativo, Tomo I, Octava Edición, Editorial Civitas S.A., Madrid, 1997. p.536.

28 Garcinı Guerra, Héctor, Derecho Administrativo, Segunda Edición, Editorial Pueblo y Educación, La Habana, 1986, p. 110. 
Otra cuestión que llama la atención es la convivencia de este Decreto Ley con las normas sectoriales que ya estaban vigentes y que también establecen un sistema contravencional en determinadas esferas específicas de protección. Al decir de Toledano Cordero y Muñoz Alfonso: “...de manera muy atinada, al definir el objeto del Decreto Ley se reconoce la validez del resto de las normas que regulan infracciones en esferas no comprendidas en este texto legal, lo que es aplicable tanto a las normas vigentes al momento de su promulgación como a las que puedan aprobarse en el futuro, siempre que ellas no se contrapongan a lo preceptuado en el texto contravencional" 29 . Ello demuestra que con el Decreto Ley 200 no se estableció un régimen contravencional general en materia de medio ambiente, tal como se puede deducir de su denominación, sino que se reconocieron en él solamente las infracciones relativas a determinados sectores específicos de protección, básicamente los que quedan bajo la estricta competencia del Ministerio de Ciencia, Tecnología y Medio Ambiente (CITMA), subsistiendo las que anteriormente habían entrado en vigor.

Desde nuestra percepción, esta sistemática empleada no es la más atinada, pues si bien es cierto que en materia de marco institucional reconocemos el principio de sectorialización, el ambiente es un sistema donde todos sus elementos se interrelacionan. Entonces también el Derecho Ambiental, las normas, principios e instituciones tienen que lograr imbricarse de forma tal que se logre la mayor uniformidad posible. De tal suerte coexisten junto al Decreto Ley 200/1999 otras normas contravencionales, incluso, algunas de vigencia anterior a la Ley 81/1997, y que constituían la legislación complementaria a la Ley 33 de 1981, ya derogada. Por citar algunos ejemplos, Decreto 179 de 1993 "Protección, uso y conservación de los suelos, y sus contravenciones", Decreto 180 de 1993, solo vigente para las contravenciones en materia de fauna y flora

29 Toledano Cordero, Dagniselys y Muños Alfonso, Yisel, “La Responsabilidad..., op.cit, p. 412. 
silvestre, Decreto 199 de 1995 "Contravenciones de las regulaciones para la protección y el uso racional de los recursos hidráulicos", Decreto 268 de 1999 "Contravenciones de las regulaciones forestales". La dispersión que se aprecia en el sistema contravencional nuestro trae consigo disímiles tropiezos en la exigencia de la correspondiente responsabilidad administrativa, los cuales serán develados en el desarrollo de este epígrafe.

Una de las virtudes que no debemos dejar de señalar de la disposición en análisis es lo relativo a las sanciones y las medidas a imponer. En este sentido prevé la imposición de multas y también, medidas disciplinarias y rescisorias. En cuanto a las multas se aprecia un aumento significativo en las cuantías a diferencia de lo que establecen las demás disposiciones contravencionales antes mencionadas, cuyas cifras son irrisorias, no correspondiéndose con la realidad económica del país. De hecho, dado que el Decreto Ley 200 data de 18 años atrás, pudiera pensarse en un aumento de las cuantías ante la diversidad de actores económicos que hoy coexisten y las actividades que realizan son, en mayor medida, proclives a deteriorar el ambiente. "La heterogeneidad económica que introducen la descentralización estatal y la presencia de diversas formas de propiedad hacen necesario un trabajo más intenso del Estado y del resto de la sociedad para contrarrestar las tendencias favorables que sacrifican el ambiente en aras del éxito económico" ${ }^{30}$. A toda costa se debe evitar esa desproporción apreciable entre la magnitud de la conducta infractora y la sanción pecuniaria que se impone, pues ello puede resultar un mecanismo a adoptar por parte del agente infractor, el cual puede optar, ante lo irrelevante de la cuantía, por afrontar la sanción y no invertir en la adopción de medidas, tecnologías, para prevenir la conducta infractora o el daño si se produce. Ello pudiera entonces convertirse en una práctica muy atractiva para los que sobreponen

\footnotetext{
30 Delgado Díaz, Carlos J, “La educación ambiental desde la perspectiva política”, en Delgado Díaz, Carlos J, (compilador), Cuba Verde, En busca de un modelo para la sustentabilidad en el siglo XXI, Editorial Félix Varela, La Habana, 2002, p. 86.
} 
el éxito económico a la protección del ambiente. A pesar de que ello pudiera ser evitado a partir de lo establecido en el artículo $15^{31}$, estamos ante un precepto que requiere de un ejercicio de la potestad discrecional de la Administración en este sentido, puesto que, tal como está redactado es un precepto facultativo.

De manera muy atinada el Decreto Ley distingue las cuantías dependiendo si el infractor es una persona natural o jurídica. Sin embargo, recordemos que hoy tenemos nuevos sujetos económicos que, aun no siendo personas colectivas, realizan actividades relevantes con potencialidad para dañar el ambiente, sus ganancias son significativas y las cuantías a exigir son las mismas que para una persona natural común. A partir del proceso de actualización del modelo económico cubano emprendido en el año 2011, los trabajadores por cuenta propia han alcanzado un lugar importante en la producción de bienes y prestación de servicios a la población, llegando a autorizarse la contratación de personal auxiliar, así como la prestación de servicios a empresas estatales ${ }^{32}$. Ello los sitúa como verdaderos empresarios, cuyo régimen jurídico no puede ser el general establecido para cualquier persona natural. La distinción debía ser, pues, entre empresarios y no empresarios, al momento de terminar la cuantía de la multa. De forma correcta, se realiza una distinción en cuanto a la moneda en que se efectuará el pago, lo cual depende de la moneda en que operen los infractores ya sean personas físicas o jurídicas.

\footnotetext{
31 Artículo 15.1: La cuantía de las multas podrá ser disminuida en la mitad o aumentada al doble de su importe, atendiendo a las características del obligado a satisfacerla y a las consecuencias de la contravención.

32 Buena parte de la normativa aplicable al trabajo por cuenta propia se condensa en el Decreto Ley No.356 del 2018 "Sobre el ejercicio del trabajo por cuenta propia", Gaceta oficial No.35, Extraordinaria de 10 de julio de 2018, con las modificaciones introducidas por el Decreto Ley No.383 de 2019; Resolución 103 del 2019 contentiva del “Reglamento del ejercicio del trabajo por cuenta propia", de la Ministra de Trabajo y Seguridad Social, y la Resolución 104 de 2019 que aprueba las actividades que se pueden ejercer en la modalidad de cuenta propia, su denominación y alcance, Gaceta Oficial No.85, Ordinaria, de 6 de noviembre de 2019. Sin perjuicio de otras disposiciones jurídicas complementarias en este ámbito.
} 
Un anhelo al que pudiera aspirarse, sin ánimos de ser utópicos, es que los recursos recaudados a partir del pago de las multas por los agentes infractores pudieran ser destinados de forma real a las acciones de mantenimiento, restauración y preservación del ambiente. Para ello se precisa del reconocimiento de esta posibilidad en las normas contravencionales y de la existencia de un mecanismo que garantice efectivamente el destino y utilización correcta de dichos recursos financieros a estos fines, más allá de la mención a esa posibilidad en la Resolución Conjunta 1, de los Ministros de Economía y Planificación y de Finanzas y Precios, de 7 de junio de 1999, en la cual se contempla como una de las fuentes de ingreso del Fondo Nacional del Medio Ambiente, a "...otros ingresos provenientes del cobro de contravenciones específicas y tasas asociadas a los ingresos obtenidos por las entidades que comercialicen productos o presten servicios de carácter ambiental o de explotación de un recurso natural, aprobados por las autoridades competentes" (inciso g del párrafo primero).

En cuanto a las medidas, el Decreto Ley permite la adopción de estas de conjunto o con independencia a la multa, lo cual significa que no es condición para aplicarlas, el haber impuesto previamente una sanción pecuniaria. En este sentido reconoce medidas disciplinarias como la amonestación y rescisorias como la prestación comunitaria, obligaciones de hacer o no hacer que impidan la continuidad de la conducta infractora, suspensión temporal o definitiva de autorizaciones, clausura temporal o definitiva, entre otras. Aquí otra de las consecuencias palpables de la dispersión que en materia contravencional impera puesto que el resto de las normas que prevén las infracciones en otras esferas de protección, no contemplan del todo estas medidas, al menos no expresamente, las cuales no solo tienen un fin punitivo sino educativo en el sentido de incentivar el cuidado del medio ambiente.

El ámbito de aplicación de la norma queda bien delimitado puesto que establece distintas esferas específicas de protección, 
siguiendo la organización que realiza la Ley 81/1997 cuando las regula. Así, es contentivo de disposiciones contravencionales relativas al proceso de Evaluación de Impacto ambiental y al otorgamiento de la Licencia Ambiental, al Sistema Nacional de Áreas Protegidas, a la zona costera y su zona de protección, a la protección del medio ambiente ante desastres naturales u otro tipo de catástrofes susceptibles de afectar el medio ambiente, a los ruidos, vibraciones y otros factores físicos, a la protección de la atmósfera, a los productos químicos tóxicos y a los desechos peligrosos.

Otro de los méritos a resaltar en la aplicación del Decreto Ley 200/1999 es la generalidad que logra a la hora de tipificar las conductas infractoras, de tal suerte que a partir de la remisión a las normas sustantivas específicas en estas materias logra una mayor perdurabilidad en el tiempo pudiendo atemperarse a los cambios que experimentan estas normativas, no siendo necesaria la modificación del texto contravencional cuando se modifican estas.

La potestad sancionadora de la cual se encuentra investida la Administración no solo es ejercida por el CITMA, sino que a la luz del artículo 16.2 y de la disposición transitoria única del Decreto Ley, se faculta a los inspectores estatales de los Organismos de la Administración Central del Estado, cuya actividad repercuta sobre la protección del medio ambiente, los del Cuerpo de Guardabosques, los de la Defensa Civil y los de la Aduana General de la República. Sin embargo, a partir de lo que establecen las legislaciones contravencionales específicas como el Decreto 179 "Protección, uso y conservación de los suelos, y sus contravenciones" o el Decreto 268 de 1999 "Contravenciones de las regulaciones forestales", se sustraen de la competencia del CITMA, recursos naturales, en este caso, el bosque y el suelo y se colocan bajo el control del mismo ente que lo explota, el Ministerio de la Agricultura (MINAGRI). Dado que las empresas dedicadas a la explotación de los bosques y los suelos se subordinan a grupos empresariales del MINAGRI, 
organismo que está llamado a protegerlos, evidentemente esto crea un conflicto de intereses que en la mayoría de las ocasiones se resuelve en contra de la protección del ecosistema y a favor de la producción maderera.

Aquí se muestra nítidamente el solapamiento de funciones característico del marco institucional cubano en materia ambiental, el cual se refleja también en el régimen contravencional a partir de la dispersión que en este ámbito existe. El cuerpo de inspectores del CITMA no ostenta competencias para actuar en estas esferas específicas de protección (suelos y bosques), sin embargo, se aprecia una ampliación de la esfera de actuación de los inspectores pertenecientes a otros organismos, con respecto a las medidas que prevé el Decreto Ley. A partir de lo que establece el artículo 16.2 estas facultades quedan restringidas a determinadas sanciones como son la multa, amonestación, comiso o resignación de los medios utilizados para cometer la contravención y de los productos obtenidos de ésta, y la obligación de hacer lo que impida la continuidad de la conducta infractora.

El procedimiento a partir del cual se imponen las sanciones previstas en el Decreto Ley 200/1999 puede iniciar a partir de una denuncia ante la autoridad facultada o por la vía de la inspección estatal. La primera de las vías es una muestra de la participación ciudadana en la protección del medio ambiente, no siendo requisito para establecer la denuncia demostrar interés legítimo con respecto a la infracción, con solo tener el conocimiento de que se produjo es suficiente. Ello es un aspecto positivo a resaltar del régimen contravencional el cual demuestra, en este sentido, estar a tono con la Ley marco, que así lo establece en su artículo 69, la cual exige además que se ponga en conocimiento de la persona denunciante las medidas impuestas y su cumplimiento si demuestra interés en conocerlo. Sin embargo, este último elemento no se encuentra precisado en el texto contravencional.

Entrando en el terreno de las inconformidades, la norma contravencional otorga la posibilidad de establecer recurso de 
apelación ante el jefe inmediato superior de la autoridad que impuso la medida. El recurso deberá interponerse dentro del término de tres días hábiles siguientes a la notificación de la medida y se resolverá dentro del término de quince días hábiles siguientes a la fecha de interpuesto. La interposición del recurso no tiene efecto suspensivo siempre que la autoridad actuante no decida lo contrario.

El proceso extraordinario de revisión también se encuentra previsto como un medio de impugnación más con el que cuenta el infractor en la vía administrativa, siempre que concurran las circunstancias que exige la norma para que pueda ser iniciado. En este sentido, es necesario que luego de la firmeza de la sanción impuesta, se conozcan hechos de los que no se tuvo noticia antes, aparezcan nuevas pruebas o se demuestre la improcedencia, ilegalidad, arbitrariedad o injusticia notoria en la imposición de la medida. Para ello el administrado cuenta con 180 días contados a partir de la firmeza de la sanción y será presentado ante el CITMA, quien estará en la obligación de resolverlo dentro del plazo de 45 días. Este proceso extraordinario de revisión no se encuentra reconocido en el resto de las normas contravencionales vigentes en materia de medio ambiente. No encontramos en las regulaciones sobre las contravenciones en materia de suelos, o de recursos forestales e hídricos, o de ordenamiento del territorio referencia alguna al procedimiento de revisión, no contando con una posibilidad más de impugnar la decisión de la Administración aun cuando concurran los requisitos que se exigen al respecto. Ello es una muestra más de la falta de uniformidad que impera respecto a la responsabilidad administrativa, la cual trae causa de la ausencia de un cuerpo legal único que de forma homogénea establezca las pautas respecto al régimen contravencional ambiental.

En torno al acceso a la vía judicial no encontramos en el Decreto Ley 200/1999 referencia alguna que la restrinja o autorice, en consecuencia, la vía judicial podrá quedar expedita pues donde la ley no distingue no cabe distinción alguna. Es 
este un aspecto en los que se observa una postura más revolucionaria, en tanto que las restantes normas complementarias de la Ley marco suelen excluir expresamente el acceso a la vía jurisdiccional ${ }^{33}$. En este sentido y a diferencia del Decreto Ley en cuestión, la mayoría de las normas contravencionales, para no ser absolutos, vedan expresamente toda posibilidad de iniciar proceso en la vía judicial, prohibiendo el acceso a la justicia en este ámbito. Esta prohibición que se refleja en la mayor parte de las normas contravencionales, devela la variación que puede experimentar el procedimiento para la exigencia de responsabilidad administrativa ambiental por el solo hecho de encontrarnos ante una esfera de protección distinta a las que recoge el Decreto Ley 200/1999, como si no estuvieran dirigidas todas a un mismo fin, la protección del ambiente. Se demuestra como las normas contravencionales complementarias a la Ley $81 / 1997$ no se encuentran a tono con el principio de la política ambiental consagrado en el artículo 4 inciso 1), "Toda persona natural o jurídica, conforme las atribuciones que la Ley le franquee, debe contar con los medios adecuados y suficientes que le permitan accionar en la vía administrativa o judicial, según proceda, para demandar el cumplimiento de lo establecido en la presente Ley y en sus disposiciones complementarias".

Al decir de Cruz SARDiÑas "La legislación complementaria heredada de la Ley No. 33 por la actual Ley del Medio Ambiente, en lo que se refiere al régimen de responsabilidad administrativa por daños al medio ambiente, necesita ser revisada, con vistas a adecuarla a los principios y normas que ha establecido el Decreto Ley No. 200"34. Ello pudiera ser una vía para otorgar solución a las incoherencias que dentro del régimen contravencional hemos podido apreciar, pero no terminaría con la dispersión normativa que prima en este orden. Sin embargo, una alternativa a tener

\footnotetext{
33 Toledano Cordero, Dagniselys y Muños Alfonso, Yisel, "La Responsabilidad..., op.cit, p. 415.

34 Cruz Sardiñas, Teresa D, “El Decreto Ley 200, De la Contravenciones en Materia de Medio Ambiente, un instrumento renovador en el ordenamiento ambiental cubano", Tesis en Opción al Grado de Máster en Derecho Ambiental, Universidad del país Vasco, España, 2000, p. 43.
} 
en cuenta, es lograr un único texto contravencional que integre todas las esferas de protección posibles, logrando de este modo una mayor uniformidad en la regulación de la responsabilidad administrativa en materia ambiental puesto que existe un objetivo en común y es el de establecer las pautas generales en el campo de las infracciones ambientales.

Interesante resulta el reconocimiento que expresamente realiza la norma contravencional en cuanto a la posibilidad de exigir, siempre que proceda, responsabilidad civil o penal, independientemente de la responsabilidad administrativa que se aplica.

En ocasiones, otros son los retos que se presentan en torno a la exigencia de responsabilidad administrativa ambiental en Cuba, no necesariamente derivados de lo estipulado en las normas jurídicas ambientales. Así, las carencias económicas que por diversos motivos afloran en el contexto cubano pueden en determinadas esferas y circunstancias específicas frenar o impedir la puesta en práctica del sistema contravencional cubano. En este sentido, podemos ver en materia de contravenciones respecto a ruidos o vibraciones que la Norma Cubana Obligatoria 26:1999, obliga a que se utilice para medir niveles sonoros dentro de las viviendas y en áreas exteriores el sonómetro de alta precisión y a su vez este sonómetro tiene que contar con una serie de requisitos también establecidos en la norma técnica, lo cual es muestra del contenido técnico reglado que caracteriza al Derecho Ambiental, a partir de la preponderancia de este tipo de normas. Entonces para determinar si estamos ante la infracción establecida en el Decreto Ley 200/1999 en su artículo 11 inciso a), necesariamente hay que hacer uso del instrumento medidor, lo cual trae consigo que, al no contar la autoridad facultada con dicho sonómetro, no podrá imponer la sanción correspondiente, aun cuando sea evidente la tipificación de la infracción. Resulta evidente que este tropiezo que se nos presenta no es consecuencia precisamente de lo estipulado en la norma obligatoria, sino que es motivado básicamente por 
razones económicas, pero dado que es una cuestión recurrente en la sociedad cubana, la posibilidad de buscar una solución alternativa, ante las dificultades que se suscitan es un tema pendiente que debe revisarse, en aras de superar estos escollos.

Se puede caracterizar la responsabilidad ambiental administrativa en Cuba como el tipo de responsabilidad predominante, aunque no excluyente, de mayor operatividad por la rapidez con la que pueden imponerse las medidas sancionadoras, con una función fundamentalmente preventiva y educativa ${ }^{35}$. No obstante, ello no significa, tal como se ha reflejado, que el sistema contravencional ambiental esté exento de ser perfectible. Variados son los desafíos que se presentan hoy en pos de lograr un régimen de responsabilidad administrativa efectivo, uniforme, y coherente con la realidad social y económica que directamente incide en la protección del ambiente.

\section{Perspectivas de la responsabilidad administrativa ambiental}

El futuro de la responsabilidad administrativa ambiental transita por el éxito que tenga el proceso ya demorado de elaboración de una ley de contravenciones que, a manera de código, integre todas las contravenciones, con independencia de cuál sea su objeto de protección. De esta forma, las contravenciones en materia de medio ambiente quedarían integradas en el mismo cuerpo legal, junto a las contravenciones relativas a otros recursos naturales, cuya gestión la realizan distintos OACEs. Ello resulta positivo, si se tiene en cuenta que se uniformaría el régimen jurídico aplicable a todas ellas en cuanto a las sanciones a imponer, circunstancias modificativas de la responsabilidad, entre otros elementos.

Un elemento a destacar de las discusiones sostenidas alrededor de las últimas versiones del anteproyecto a las que se

35 Cánovas GonzÁlez, Daimar, La responsabilidad por daños ambientales..., op.cit, p.11. 
ha tenido acceso $^{36}$, es la propuesta de que se utilice para la determinación de las multas a pagar un sistema de unidades móviles, y no nominal, como el que hasta ahora se emplea en el país. Una de las dificultades de todo el sistema contravencional cubano es precisamente la escasa cuantía de las multas, al haber mutado de forma considerable el contexto económico en que fueron dictadas, y eso es válido incluso para el Decreto Ley 200/1999, cuyas cuantías son superiores. La utilización del salario mínimo o el salario medio nacional como unidad de medida, contribuiría a mantener actualizada la norma contravencional, sin que resulte afectada en ese sentido por el trascurso del tiempo.

Una cuestión que aún debe ser zanjada es la creación a partir de dicha Ley de un único cuerpo de inspectores facultados para imponer las sanciones, cualquiera que sea la naturaleza de la contravención detectada. La especialización de las normas ambientales hace necesario que exista al menos un cuerpo independiente o adjunto, que pueda contar con la capacitación suficiente para detectar las infracciones, que pasarían desapercibidas para personal que no cuente con dicha preparación. Las contravenciones en materia ambiental necesitan del operador de la norma ciertas habilidades y conocimientos especializados que no pueden crearse en personas que tengan que atender de forma simultánea múltiples objetos de protección.

Por otra parte, el reconocimiento explícito en la Ley de Medio Ambiente al derecho a un medio ambiente sano, y el acceso a la justicia como una exigencia suya (artículo 4, incisos a y l), hace que daba ampliarse la posibilidad de impugnar la decisión administrativa en vía judicial, extendiendo la solución de la norma contravencional ambiental para todas las materias abarcadas. No es posible que la Administración ejercite

\footnotetext{
36 Del mes de mayo de 2013. Aunque se continua trabajando en la misma, como reconoció públicamente la Viceministra de Justicia, Pilar Varona Estrada. https://www.prensa-latina. cu/index.php? $0=$ rn\&id=384822\&SEO=cuba-minjus-garantiza-servicios-a-la-poblacion-pesea-pandemia, consultado en 2 de agosto de 2020: 1: 50 pm.
} 
su potestad sancionadora y los recursos queden en el ámbito de los procedimientos administrativos internos. El respeto al debido proceso exige la posibilidad de revisión judicial, sobre todo si se tiene en cuenta que se puede afectar el patrimonio del infractor, e incluso obligarlo a determinada prestación de carácter personal.

El régimen contravencional que se dicte debe evitar el establecimiento de excepcionalidades para determinados sectores económicos o espacios del territorio nacional. Si bien las contravenciones en materia ambiental constituyen conductas de menor peligrosidad social, la funcionalidad del sistema exige que se aplique a todos y en todas partes por igual, so pena de que la credibilidad del sistema y de toda la Administración se resienta. Si la norma general ha sido fruto de un consenso, su contenido debe imponerse, por muy estratégico que sea el proyecto o la instalación. Si el dictado no va a aplicarse en casos particulares, es preferible no incluirlo en la disposición, para bien del Derecho Ambiental y el ordenamiento jurídico cubano.

Por último, y no menos importante, es patente la necesidad de un procedimiento administrativo común ${ }^{37}$. El objetivo de un mismo procedimiento para la imposición de las sanciones, y su impugnación posterior por parte del infractor, es todavía más prioritario que reunir en mismo cuerpo legal todas las contravenciones, con independencia del bien jurídico tutelado. Al menos, ofrecería mayor seguridad jurídica y evitaría la dispersión en la tramitación, pues al día de hoy, cada disposición contravencional regula un procedimiento administrativo diferenciado, lo que hace muy difícil la tarea para el operador jurídico, que tiene que posicionarse en un conjunto heterogéneo de procedimientos, dictados en distintos contextos y con diferentes objetivos.

37 Lezcano Calcines, José Ramón, "Procedimiento administrativo" en, Autores Varios, Estudios de Derecho Administrativo cubano, Editorial Félix Varela, La Habana, 2002, pp. 275-276. 
Son solo algunas cuestiones que se espera sean parte de la régimen contravencional general, y por tanto, del modo en que sea impuesta la responsabilidad administrativa ambiental en Cuba. El diseño del modelo futuro debe hacer un balance de la aplicación de la normativa vigente, destacando sus valores al igual que sus limitaciones, para que la disposición que se dicte, sea, al mismo tiempo, hija de la experiencia nacional y de lo más avanzado de la doctrina y la legislación comparada. Ahí está el reto. 